\title{
BMJ Open CHI study: protocol for an observational cohort study on ageing and mental health in community-dwelling older adults
}

\author{
Rachael Zhi Yi Lee (D) , ${ }^{1}$ Junhong Yu, ${ }^{1}$ Iris Rawtaer, ${ }^{2}$ Patrick Finbarr Allen, ${ }^{3,4}$ \\ Zhiming Bao, ${ }^{5}$ Lei Feng, ${ }^{1}$ Qiushi Feng, ${ }^{6,7}$ Jeong Kyu Lee, ${ }^{8}$ Chin Tat Lim, ${ }^{9}$ \\ Lieng Hsi Ling, ${ }^{10,11}$ Leng Leng Thang, ${ }^{7,12}$ Thet Naing, ${ }^{13}$ D Y Wang, ${ }^{14}$ Kai Zhen Yap, ${ }^{15}$ \\ EH Kua, ${ }^{1,16}$ Rathi Mahendran ${ }^{1,17}$
}

To cite: Lee RZY, Yu J, Rawtaer I, et al. CHI study: protocol for an observational cohort study on ageing and mental health in communitydwelling older adults. BMJ Open 2020;10:e035003. doi:10.1136/ bmjopen-2019-035003

- Prepublication history for this paper is available online. To view these files, please visit the journal online (http://dx.doi. org/10.1136/bmjopen-2019035003).

Received 15 0ctober 2019 Revised 08 February 2020 Accepted 09 April 2020
Check for updates

(C) Author(s) (or their employer(s)) 2020. Re-use permitted under CC BY-NC. No commercial re-use. See rights and permissions. Published by BMJ.

For numbered affiliations see end of article.

Correspondence to Professor Rathi Mahendran; pcmrathi@nus.edu.sg

\section{ABSTRACT}

Introduction Ageing is associated with a multitude of healthcare issues including dementia, depression, frailty, morbidity associated with chronic disease and high healthcare utilisation. With Singapore's population projected to age significantly over the next two decades, it has become increasingly important to understand the disease burden and etiological process among older adults. The Community Health and Intergenerational study aims to holistically examine ageing in place by investigating the resilience and vulnerability factors of the ageing process in the biological, psychological and social domains within the environment.

Methods and analysis Using a cohort multiple randomised controlled trial design, comprehensive health profiles of community-dwelling older adults will be collected. The objective is to recruit 1000 participants (aged 60-99 years) living in the western region of Singapore within a period of 3 years (2018-2020). Assessments include basic sociodemographic, physical health and function (cardiac, oral and blood profiles and visual function), cognitive functioning, daily functioning, physical fitness, emotional state, free-flowing speech, sleep quality, social connectedness, caregiver burden, intergenerational communication, quality of life, life satisfaction, attitudes to ageing and gratitude and compassion. Results from the cohort will enable future studies to identify at-risk groups and develop interventions to improve the physical and mental health and quality of life of older adults.

Ethics and dissemination Approval of the cohort study by the National University of Singapore Institutional Review Board (NUS-IRB Reference code: H-17-047) was obtained on 12 October 2017. Written consent will be obtained from all participants. Findings from the cohort study will be disseminated by publication of peer-reviewed manuscripts, presentations at scientific meetings and conferences with local stakeholders.

\section{INTRODUCTION}

\section{Background}

The WHO estimates that the global population of older adults aged 60 years and above
Strengths and limitations of this study

- This ongoing study will be among the first few cohort studies that comprehensively investigate the health profiles of older adults in Singapore.

- Results of this study may contribute to a better understanding of vulnerability and resiliency factors of ageing.

- Using a cohort multiple randomised controlled trial design will enable subsequent interventional studies to identify at-risk groups and test the feasibility of clinical interventions and community programmes that aim to improve health outcomes in older adults.

- Due to sample size and cost considerations, the study lacks other in-depth measures; while restricted recruitment limits generalisability of the results.

- The extensive range of findings from this study will provide useful health information about older adults that is relevant to clinicians, researchers and policymakers in Singapore.

will rise from 900 million in 2015 to 2 billion in $2050 .{ }^{1}$ In Singapore, the proportion of residents aged above 65 years nearly doubled from $8.8 \%$ in 2009 to $14.4 \%$ in 2019 and is projected to be $25 \%$ by $2030 .^{2}$ This poses a challenge as ageing is associated with a plethora of healthcare issues and high healthcare utilisation. Over the years, researchers have conducted nation-wide studies in Singapore to understand age-related diseases ${ }^{34}$ and modifiable factors to promote healthy ageing. ${ }^{56}$ Previous research has adopted a multidimensional framework (eg, WHO's definition of health) to better understand the ageing process and healthcare-related needs. ${ }^{7}$ Using a similar framework, the Community Health and Intergenerational (CHI) study adopts Engel's ${ }^{8}$ biopsychosocial model of health and disease to holistically examine ageing in place by 
collecting comprehensive health profiles of older adults in Singapore.

To date, cohort studies are shifting towards using holistic frameworks to observe ageing and health in the community. The Healthy Older People Everyday study $(\mathrm{n}=1051)$ is one such study that sought to assess physical and mental health among community-dwelling older adults (aged $\geq 65$ years) through basic health screening as well as a health survey. ${ }^{9}$ Although the study used objective screening tools (eg, mini-mental state exam and physical fitness tests), it comprised mostly of self-reported measurement. The authors also suggested the need for more robust and comprehensive tools to be considered such as the Geriatric Depression Scale. Although other larger age-related cohort studies such as the Australian Imaging Biomarkers and Lifestyle study ${ }^{10}$ and Alzheimer's Disease Neuroimaging Initiative ${ }^{11}$ are notable studies that have collected a wide range of measures (eg, clinical, cognitive, neuroimaging, lifestyle and genetic data), nonetheless the focus was largely on the treatment and progression of Alzheimer's disease $(\mathrm{AD})$. Further research is needed to assess other health-related determinants of older adults in the healthy ageing spectrum such as oral health assessments, cardiovascular investigations, speech analysis and olfactory measures. The Well-being of the Singapore Elderly study $(\mathrm{n}=2565)$ was another comprehensive study that included face-to-face interviews and physical examination; however, it lacked laboratory measurements and did not assess cardiovascular and other physical health risks. ${ }^{12}{ }^{13}$ Research using objective measures to determine physical (eg, blood markers or echocardiography) and cognitive (eg, neurocognitive assessments) health status is needed to complement self-reported data. In terms of oral health, there appears to be an association between dental disease, tooth loss and onset of frailty. ${ }^{14}$ It is plausible that this may be mediated through triggering of inflammatory processes by pathogens from periodontal tissues, but there is a lack of longitudinal data to confirm this hypothesis.

There have been a few cross-sectional cohort studies carried out on older adults in the local context; these include the Singapore Longitudinal Ageing Study (SLAS) and the Diet and Healthy Ageing (DaHA) cohort. Conceived in 2003, the SLAS ( $\mathrm{n}=6183$ ) aimed to provide a community-based cohort of older adults (aged 55 years and above) for subsequent clinical-based interventions. ${ }^{7}$ Results from the ongoing study found new prevalence rates $^{15}$ and associations. ${ }^{6}{ }^{16}$ Participants from SLAS were also identified to join subsequent intervention studies such as a computer training randomised controlled trial (RCT) that was found to improve cognitive functioning. ${ }^{17}$ On the other hand, the DaHA (cohort) study placed emphasis on dietary factors and its association with healthy ageing and reduced risk of age-related medical conditions. ${ }^{5}$ For instance, the bioactive compounds found in mushroom and long-term tea consumption were associated with delay in cognitive impairment and reduced depression/anxiety symptoms, respectively. ${ }^{5}{ }^{18}$ The cohort study later invited suitable subjects to participate in subsequent non-pharmacological RCTs that aimed to improve cognitive and psychological health-art therapy and music reminiscence activity, ${ }^{19}$ mindfulness awareness programme ${ }^{20}$ and horticultural therapy. ${ }^{21}$

Although the aforementioned studies on older adults documented valuable findings, some of them mainly focused on the treatment and progression of $\mathrm{AD}$, while most studies did not incorporate other important measures of health such as detailed oral health examination, cardiovascular assessments and biomarkers, olfactory measures or speech analysis. More observational studies using in-depth and culturally relevant assessments of older adults in the healthy ageing spectrum are needed. This calls for greater integration of health, psychosocial and environmental resources through close collaborations among clinicians, researchers and community partners. Thus, the CHI study aims to holistically investigate factors associated with healthy ageing in a community setting using a broad range of health-related measures.

\section{Research aims}

The primary goal is to examine the health profiles of older adults and form meaningful associations based on the following:

a. Biological factors such as the physical health condition (eg, cardiac, oral, blood profiles, vital signs and visual function), physical fitness/function, medical history and medication use, and nutritional status.

b. Psychological factors such as the cognition, emotional state (anxiety and depression symptoms), sleep quality, attitudes, values, satisfaction with life and quality of life.

c. Social factors such as social support, intergenerational relationships and the impact on family members.

Second, this study also acts as a recruitment platform for future interventional studies (eg, feasibility or fullscale trial) to identify at-risk groups or normal ageing participants. The cohort data will enable the development and evaluation of pharmacological and psychosocial interventions targeted at improving health outcomes for older adults. Specifically, data will be used to identify at-risk groups such as (but not limited to) older adults with subsyndromal depression or anxiety, mild cognitive impairment, medical conditions (eg, hyperlipidemia, diabetes, hypertension), at-risk of cardiovascular diseases, oral diseases, speech impairment or sleep apnea. Other future substudies will also explore culturally relevant psychosocial factors related to healthy ageing such as intergenerational communication, attitudes to ageing, social networks, satisfaction with life and many more.

\section{METHODS AND ANALYSIS}

\section{Study design}

The CHI study adopts a cohort multiple RCT (cmRCT) design, whereby the cohort provides capacity for multiple RCTs over time. ${ }^{22}$ Using a cmRCT design may increase 
efficiency in trial recruitment and potentially lower attrition rates. ${ }^{23}$ Hence, the cmRCT design is adopted to determine biopsychosocial factors involved in the ageing process and subsequently introduce interventions that can mitigate ageing-related issues such as cognitive and psychological health, diet, medication adherence, speech impairments, oral hygiene. The ongoing CHI study has started data collection on 1 February 2018. It will be conducted in two phases. Phase I comprises of a crosssectional cohort study (baseline) detailed in this paper. Participants enrolling for the CHI cohort will be given the option of allowing their data to be used for analyses and in identifying them for future research interventions (ie, Phase II) or for comparison purposes for intervention trials. Details of the Phase II interventions will be published in full manuscripts separately.

\section{Study sample}

This 3-year cohort study targets to recruit 1000 communitydwelling older adults in Singapore. Participants aged between 60 and 99 years of any gender and ethnic group will be eligible for the study. Illiterate participants are also eligible for the study; however, they will be excused from the Cambridge Neuropsychological Test Automated Battery. Assessments will be conducted in languages such as English, Mandarin, Malay and Chinese dialect (eg, Hokkien), depending on the subject's preference.

In collaboration with Presbyterian Community Services (PCS), the main study site will be held at a local seniors' activity centre, Hannah Seniors Activity Centre (HSAC), located within the community in the central west district of Singapore. Confirmation of the sociodemographic data of over 3000 older adults in the Anak Bukit area (ie, a subzone of the central west district) has been verified through the Department of Statistics Singapore. ${ }^{24}$ Data from PCS also indicated an estimate of 1000 older adults within a 20-block radius from the activity centre at Toh Yi. Recruitment is restricted to the central west district of Singapore.

\section{Patient and public involvement}

Participants in this study were not involved in the development of the study design or objectives. The research design and objectives were developed by the investigators of this study and underwent review by a board of academic advisors affiliated to the National University of Singapore Mind-Science Centre. PCS, a community partner, provided the study site (eg, quiet rooms in HSAC). In addition, information about the study procedures and recruitment process were shared with staff from PCS prior to data collection.

\section{Procedure}

Older adults will be recruited from residences via door-todoor visits by research nurses and research assistants in the Toh Yi, Anak Bukit area and other areas within the district encompassed by a $10 \mathrm{~km}$ radius from the HSAC. Eligible individuals will also be recruited onsite from HSAC, community centres, resident corners, senior activity centres and residences within the recruitment area-advertisement flyers will be made available for visitors to the respective centres and word of mouth. Interested individuals will be invited to HSAC at their convenience. Nonambulant individuals who are keen to participate in the study will have their consent taken in their own homes. A member of the research team will explain the study in detail and time will be given for individual to consider before written consent is given.

Participants will be invited to complete up to six separate visits, estimating to a total of 11 hours; they will be scheduled to complete five visits to HSAC and one to NUS Cardiovascular Imaging Core Lab at their earliest convenience. Data will be obtained through semistructured face-to-face interviews (visits 1 and 2), neuropsychological assessments (visits 3 and 4), biological specimen collection (blood and dental samples), dental examination (visit 5) and cardiovascular examination (visit $6)$, details of which are given in table 1 . Non-ambulant participants will be assessed in their own homes and will only have to complete visits $1-3$. Trained research assistants and certified nurses will conduct visits $1-4$ and blood venepuncture, while certified dentists and medical sonographers will conduct visits 5 and 6 , respectively. Moreover, experts will provide referral letters to participants for further follow-up if incidental findings should arise from assessments such as neuropsychological tests, depression/anxiety screening, oral health examination, blood tests and/or cardiovascular examination.

\section{Outcome measures}

A wide range of data, spanning across several health domains, will be collected. Instruments and physical examinations were introduced by the investigators of this study that comprises of experts in psychiatry, cardiology, dentistry, otolaryngology, sociology, pharmacy, family and population research, linguistics, public health, orthopaedics and ophthalmology. These measures have been validated in the local context. ${ }^{15}{ }^{25-42}$ It also comprises novel scales that will be used to test for validity in this sample.Table 1 provides an overview of the measures to be collected.

\section{Data storage and analysis}

Participants will be assigned a subject identification number (SID). Their corresponding data including questionnaire responses, audio recording, assessment records and biological samples will be kept anonymous and coded with the same assigned SID for consistency. All hardcopy data responses will be checked by two personnel to minimise missing data. Hardcopy coded data collected will be entered and stored on a standalone computer, and softcopy data will be password protected. Furthermore, all hardcopy data will be stored in a designated secured and locked space, accessible only to the selected personnel.

In general, demographic variables will be presented as descriptive summaries such as mean $\pm \mathrm{SD}$, median, 


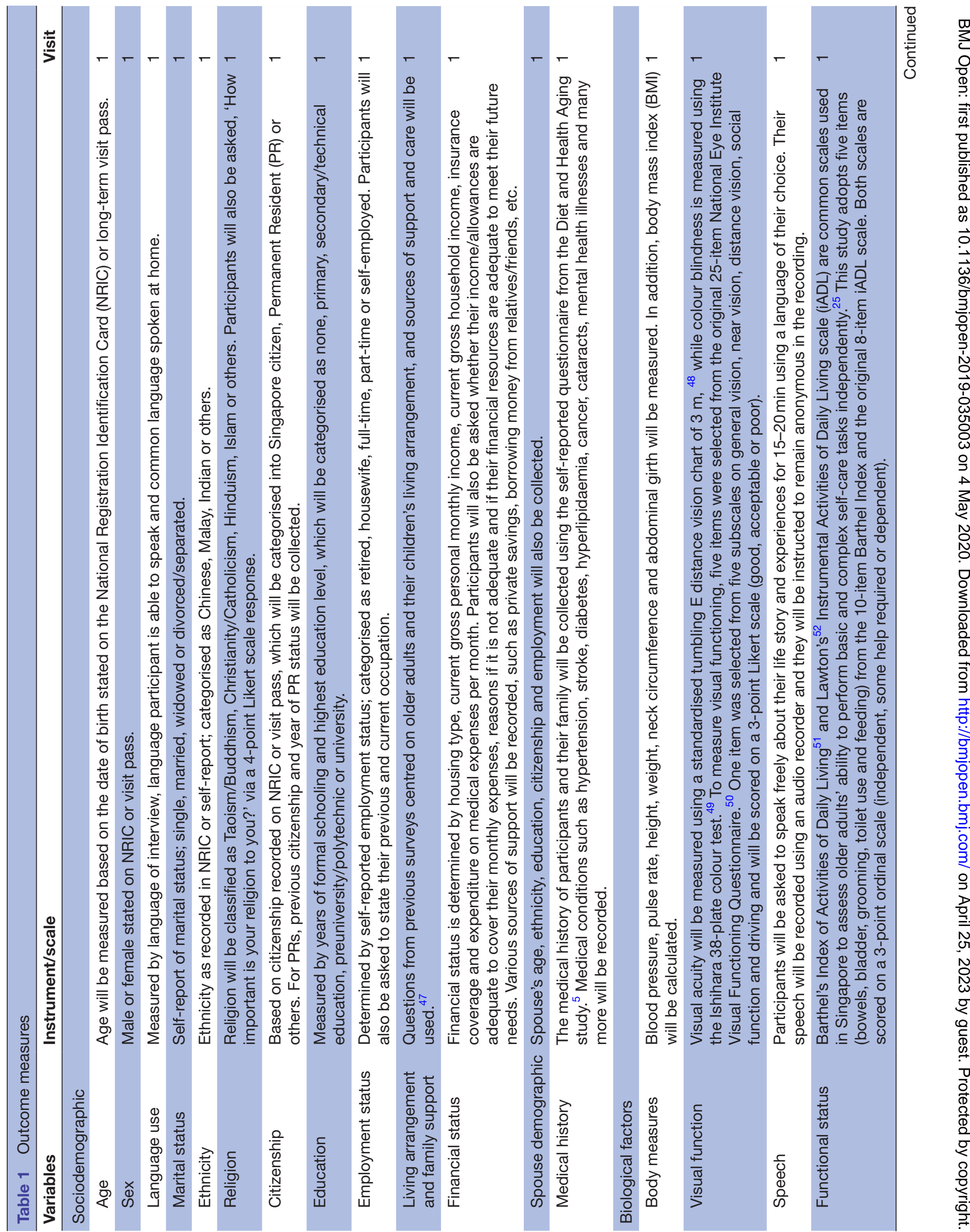

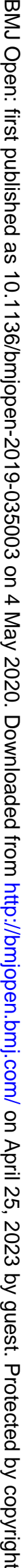




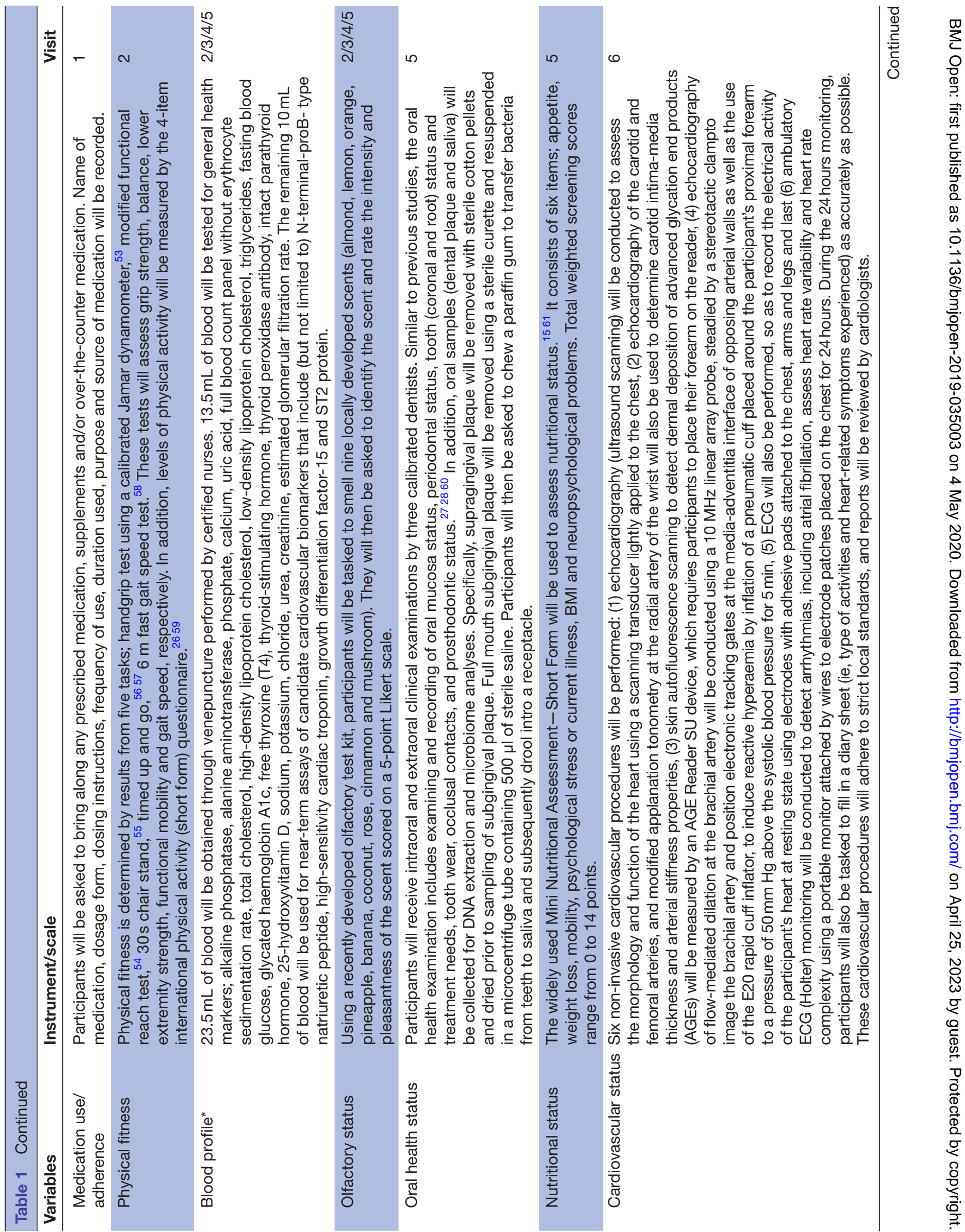




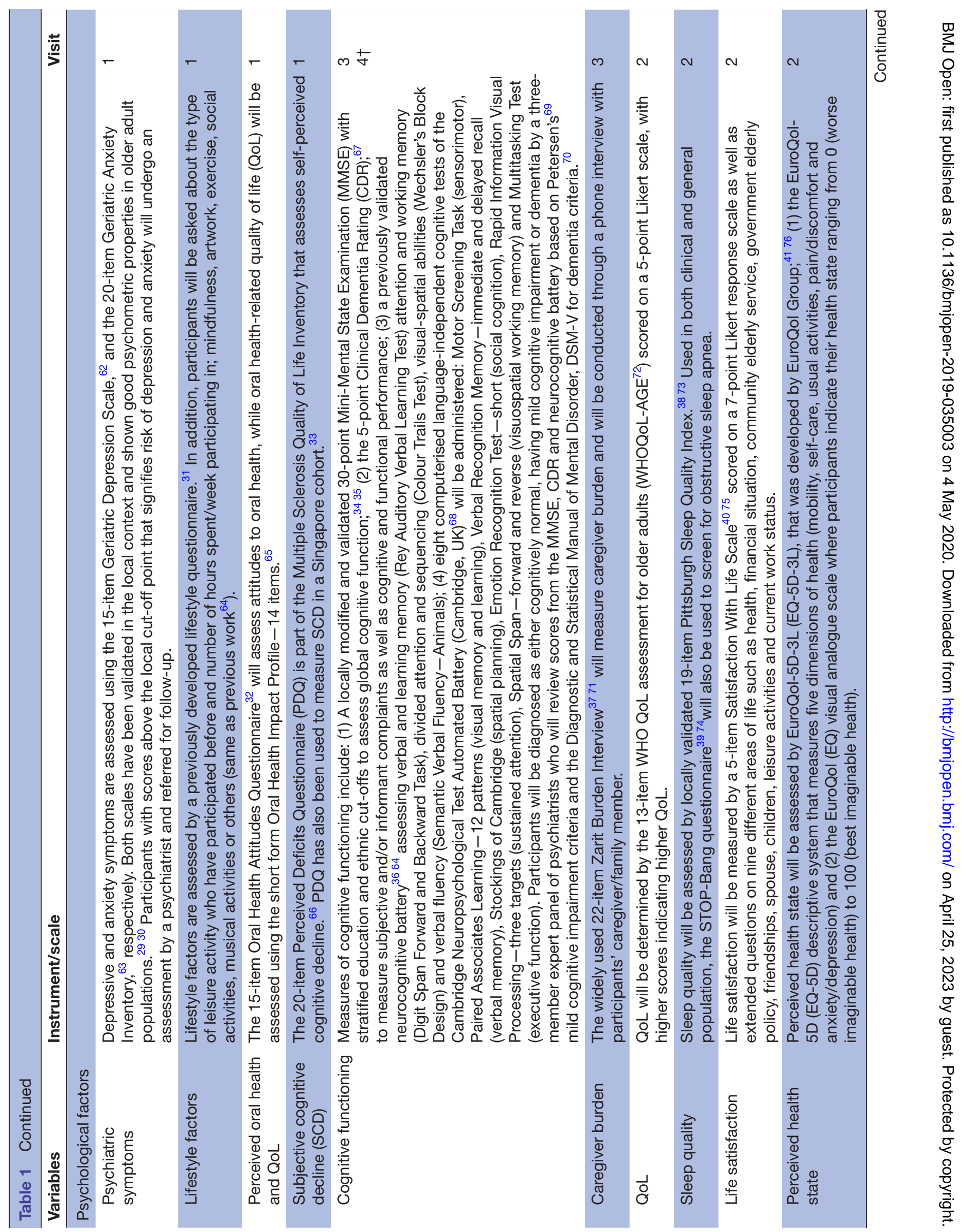




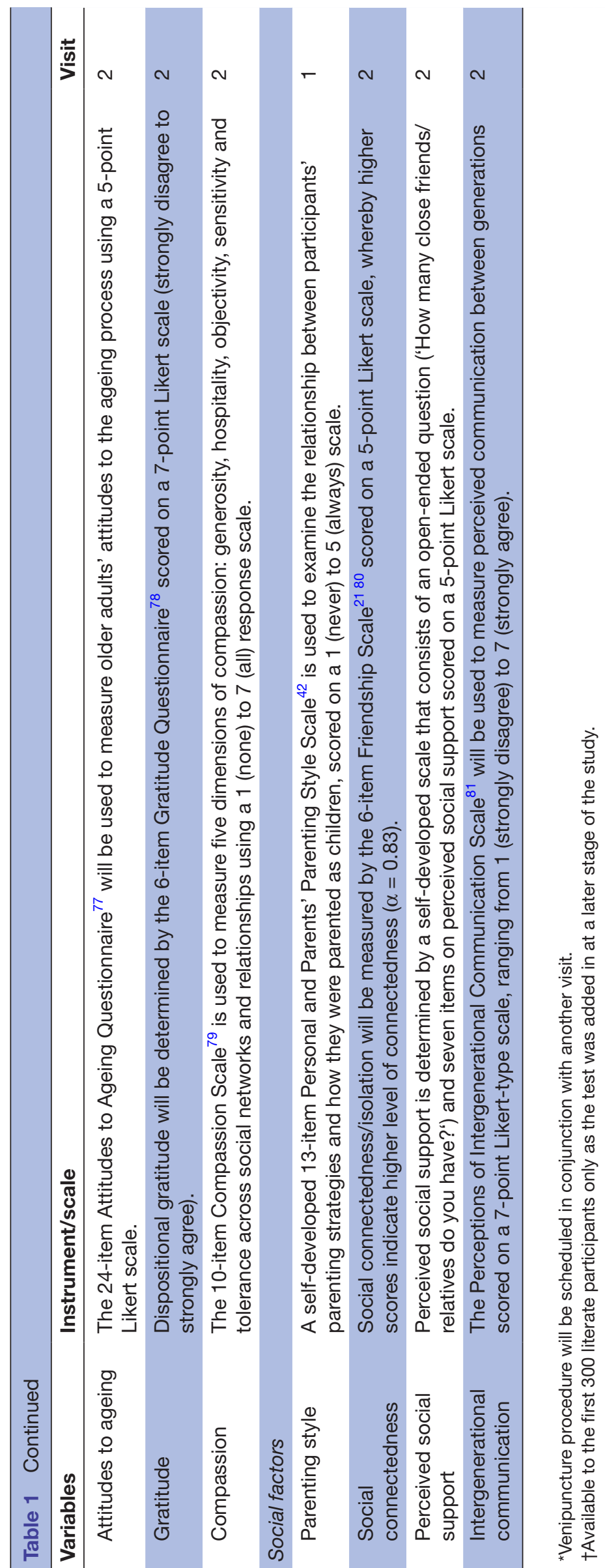


percentages for continuous variables and proportions for categorical variables. Univariate and multivariate linear regression analyses will be conducted to determine associations between continuous outcomes; logistic regressions will be used for dichotomous outcomes. Specifically, group differences (between cognitive diagnoses or self-reported medical conditions) will be analysed using independentsample t-tests and analysis of variance. Relationships between physical and mental health, psychosocial and demographic variables will be analysed using multiple regressions and structural equation models. In addition, mixture models will be used to identify subgroups of participants based on their psychosocial, physical and mental health characteristics. Prediction modelling will also be attempted using the new covariates under study (eg, attitudes to ageing and intergenerational influence). $\mathrm{P}$ values of $<0.05$ will be considered statistically significant.

\section{ETHICS AND DISSEMINATION}

Ethics approval from the National University of Singapore Institutional Review Board (NUS-IRB Reference code: H-17-047) was obtained on 12 October 2017. The CHI study will be conducted in accordance with the principles of Good Clinical Practice and adhere to the Human Biomedical Research Act which provides a legal framework for researchers in Singapore to conduct research and the use of human tissue. ${ }^{43}$

Written informed consent will be obtained from all the participants after objectives and procedures of the research are fully explained to them by a member of the research team. Participants will also be informed that they can withdraw from the research at any time without giving any reasons. In addition, participants will be given the option of (1) providing their coded human biological materials and data for use in future research, (2) being recorded for the free flow speech segment and (3) being contacted for future intervention studies, incidental findings, changes to the research and follow-up appointment for memory concerns. Participants with dementia will also be asked to invite their legally acceptable representatives to the consent-taking process and data collection. The research team will ascertain that any persons making a decision on behalf of the participant with dementia acts in the best interest of the participant and takes into account of the participant's wishes and feelings.

Results from the cohort study will be disseminated by publication of peer-reviewed manuscripts, presentations at scientific meetings and/or conferences with local stakeholders. The researchers may also communicate aggregated results to members of the public and clinical professionals through ad hoc meetings/events or mass media releases.

\section{DISCUSSION}

Using a cmRCT design, the CHI study seeks to explore vulnerability and resiliency factors associated with ageing with subsequent clinical trials of interventions and community programmes that could potentially hold translational significance. The study intends to recruit 1000 older adults and collect a comprehensive set of biological, psychological and social data. Meaningful associations between outcome measures found will provide significant information on the physical and mental health of older adults in Singapore. Results will also help identify at-risk groups of older adults and test out subsequent interventions targeted at improving health outcomes. In addition, having an interdisciplinary team of investigators enables the introduction of in-depth and novel health assessments such as oral examination, cardiovascular investigations, olfactory test and speech analysis. Given the limited sample size and cost considerations, this study excluded genetic and other in-depth measures (eg, neuroimaging and Structured Clinical Interview for Diagnostic and Statistical Manual of Mental Disorders Fifth Edition, SCID-5) which could have added value to findings. Moreover, several ageing cohort studies in Singapore ${ }^{44-46}$ have previously collected the above-mentioned data; hence, due to the limited resources, these measures were excluded in favour of other novel measures. Recruitment of participants in a confined area may also affect generalisability of the results. Nevertheless, the CHI cohort is culturally relevant and will provide clinicians, researchers and policymakers with information on improving the physical and mental health of older adults in Singapore.

\section{Author affiliations}

${ }^{1}$ Department of Psychological Medicine, Yong Loo Lin School of Medicine, National

University of Singapore, Singapore

${ }^{2}$ Department of Psychiatry, Sengkang General Hospital, Singapore

${ }^{3}$ Dean, Faculty of Dentistry, National University of Singapore, Singapore

${ }^{4}$ Centre for Oral Health, National University Health System, Singapore

${ }^{5}$ Department of English Language and Literature, Faculty of Arts and Social Science, National University of Singapore, Singapore

${ }^{6}$ Department of Sociology, National University of Singapore, Singapore

${ }^{7}$ Centre for Family and Population Research, National University of Singapore, Singapore

${ }^{8}$ Saw Swee Hock School of Public Health, National University of Singapore, Singapore

${ }^{9}$ Department of Orthopaedic Surgery, Yong Loo Lin School of Medicine, National University of Singapore, Singapore

${ }^{10}$ Department of Medicine, Yong Loo Lin School of Medicine, National University of Singapore, Singapore

${ }^{11}$ Department of Cardiology, National University Heart Centre, Singapore

${ }^{12}$ Department of Japanese Studies, National University of Singapore, Singapore

${ }^{13}$ Department of Ophthalmology, National University Health System, Singapore

${ }^{14}$ Department of Otolaryngology, Yong Loo Lin School of Medicine, National University of Singapore, Singapore

${ }^{15}$ Department of Pharmacy, Faculty of Science, National University of Singapore, Singapore

${ }^{16}$ Department of Psychological Medicine, National University Hospital, Singapore

${ }^{17}$ Academic Development Department, Duke-NUS Medical School, Singapore

Acknowledgements The authors wish to thank Presbyterian Community Services for their valuable support. The authors would also like to thank the research team made up of research assistants (Mr Jonathan Wong, Ms Tan Xin Yi, Mr Jonathan Louis Chia, Ms PetrinaQuek, Ms Madeline Han, Ms Khor Ting Fang, Ms Savannah Siew, Ms Amanda Phoa, Ms Lim Xin Ying and Ms Yap Ai Che), dental practitioners (A/Prof Wong MunLoke, A/Prof Tan Kai Soo, Dr Lee Yun Hui, Dr Tan Mei Na, Dr Rakhi Mittal), nurses (Ms Ng Siew Yee and Ms Adeline Teo) and sonographers (Ms Gong 
Lingli, Ms HazlizaHazli and Ms Josephine BerbosoLunaria) who contributed to the execution of the Community Health and Intergenerational Study. Special thanks to Prof A. Mark Richards (NUS Cardiovascular Research Institute) for the laboratory support provided as well as $\mathrm{Dr}$ Cao Luwen for her transcription work and inputs (audio recordings).

Contributors RM, EHK and IR made a significant contribution to the conception of the study and implementation of the protocol. LF, PFA, LHL, ZB, DYW, LLT, KZY, QF, JKL, CTL and TN participated in the design of the study. RM initiated and conducted the study with a team of researchers (including PFA, LHL and RZYL) and is the primary author of the manuscript. RM, RZYL and JY prepared the first draft of the manuscript. RM, JY, RZYL, ZB and PFA made revisions to the manuscript. All authors read and approved the final version of the manuscript.

Funding The $\mathrm{CHI}$ Study is a research project under the National University of Singapore Mind-Science Centre (NUS MSC) and is funded by donation grants: (1) Hong Kong and Shanghai Bank Corporation grant for community projects and (2) funding from Kwan Im Thong Hood Cho Temple for NUS MSC's Dementia Prevention Program.

\section{Competing interests None declared.}

Patient consent for publication Not required.

Provenance and peer review Not commissioned; externally peer reviewed.

Open access This is an open access article distributed in accordance with the Creative Commons Attribution Non Commercial (CC BY-NC 4.0) license, which permits others to distribute, remix, adapt, build upon this work non-commercially, and license their derivative works on different terms, provided the original work is properly cited, appropriate credit is given, any changes made indicated, and the use is non-commercial. See: http://creativecommons.org/licenses/by-nc/4.0/.

\section{ORCID iD}

Rachael Zhi Yi Lee http://orcid.org/0000-0001-9844-941X

\section{REFERENCES}

1 World Health Organisation. Ageing and health. Available: https:// www.who.int/news-room/fact-sheets/detail/ageing-and-health [Accessed Oct 2015].

2 Department of Statistics, Singapore. Population trends: ageing population 2019. Available: https://www.singstat.gov.sg/find-data/ search-by-theme/population/population-and-population-structure/ visualising-data/population-trends [Accessed Oct 2019]

3 Heng DM, Lee J, Chew SK, et al. Incidence of ischaemic heart disease and stroke in Chinese, Malays and Indians in Singapore: Singapore cardiovascular cohort study. Ann Acad Med Singapore 2000;29:231-6.

4 Subramaniam M, Chong SA, Vaingankar JA, et al. Prevalence of dementia in people aged 60 years and above: results from the wise study. J Alzheimers Dis 2015;45:1127-38.

5 Chan S-P, Yong PZ, Sun Y, et al. Associations of long-term tea consumption with depressive and anxiety symptoms in communityliving elderly: findings from the diet and healthy aging study. J Prev Alzheimers Dis 2018;5:21-5.

$6 \mathrm{Ng} \mathrm{T-P,} \mathrm{Feng} \mathrm{L,} \mathrm{Niti} \mathrm{M,} \mathrm{et} \mathrm{al.} \mathrm{Tea} \mathrm{consumption} \mathrm{and} \mathrm{cognitive}$ impairment and decline in older Chinese adults. Am J Clin Nutr 2008;88:224-31.

$7 \mathrm{Ng}$ TP, Broekman BFP, Niti M, et al. Determinants of successful aging using a multidimensional definition among Chinese elderly in Singapore. Am J Geriatr Psychiatry 2009;17:407-16.

8 Engel GL. The clinical application of the biopsychosocial model. Am J Psychiatry 1980;137:535-44.

9 Merchant RA, Chen MZ, Tan LWL, et al. Singapore healthy older people everyday (hope) study: prevalence of frailty and associated factors in older adults. J Am Med Dir Assoc 2017;18:734.e9-734. e14.

10 Ellis KA, Bush Al, Darby D, et al. The Australian imaging, biomarkers and lifestyle (AIBL) study of aging: methodology and baseline characteristics of 1112 individuals recruited for a longitudinal study of Alzheimer's disease. Int Psychogeriatr 2009;21:672-87.

11 Petersen RC, Aisen PS, Beckett LA, et al. Alzheimer's disease neuroimaging Initiative (ADNI): clinical characterization. Neurology 2010;74:201-9.

12 Seow LSE, Subramaniam M, Abdin E, et al. Hypertension and its associated risks among Singapore elderly residential population. Journal of Clinical Gerontology and Geriatrics 2015;6:125-32.
13 Teh WL, Abdin E, Vaingankar JA, et al. Prevalence of stroke, risk factors, disability and care needs in older adults in Singapore: results from the wise study. BMJ Open 2018;8:e020285

14 Ramsay SE, Papachristou E, Watt RG, et al. Influence of poor oral health on physical frailty: a population-based cohort study of older British men. J Am Geriatr Soc 2018;66:473-9.

15 Wei K, Nyunt MSZ, Gao Q, et al. Frailty and malnutrition: related and distinct syndrome prevalence and association among communitydwelling older adults: Singapore longitudinal ageing studies. J Am Med Dir Assoc 2017;18:1019-28.

$16 \mathrm{Ng}$ TP, Feng L, Nyunt MSZ, et al. Metabolic syndrome and the risk of mild cognitive impairment and progression to dementia: followup of the Singapore longitudinal ageing study cohort. JAMA Neurol 2016;73:456-63.

17 Lee TS, Quek SY, Goh SJ, et al. A pilot randomized controlled trial using EEG-based brain-computer interface training for a Chinesespeaking group of healthy elderly. Clinlnterv Aging 2015;10:217-27.

18 Feng L, Cheah IK-M, Ng MM-X, et al. The association between mushroom consumption and mild cognitive impairment: a community-based cross-sectional study in Singapore. J Alzheimers Dis 2019;68:197-203.

19 Mahendran R, Gandhi M, Moorakonda RB, et al. Art therapy is associated with sustained improvement in cognitive function in the elderly with mild neurocognitive disorder: findings from a pilot randomized controlled trial for art therapy and music reminiscence activity versus usual care. Trials 2018;19:615.

20 Klainin-Yobas P, Kowitlawakul Y, Lopez V, et al. The effects of mindfulness and health education programs on the emotiona state and cognitive function of elderly individuals with mild cognitive impairment: a randomized controlled trial. J Clin Neurosci 2019;68:211-7.

21 Chan HY, Ho RC-M, Mahendran R, et al. Effects of horticultural therapy on elderly' health: protocol of a randomized controlled trial. BMC Geriatr 2017;17:192.

22 Relton C, Torgerson D, O'Cathain A, et al. Rethinking pragmatic RCTs: introducing the 'cohort multiple RCT' design. BMJ 2010;340:c1066.

23 Viksveen P, Relton C, Nicholl J. Benefits and challenges of using the cohort multiple randomised controlled trial design for testing an intervention for depression. Trials 2017;18:308.

24 Department of Statistics, Singapore. Population trends, 2017. Department opf Statistics, Ministry of Trade and Industry, Republic of Singapore. Available: https://www.singstat.gov.sg/-/media/files/ publications/population/population2017.pdf [Accessed Oct 2019].

25 Feng L, Zin Nyunt MS, Gao Q, et al. Cognitive frailty and adverse health outcomes: findings from the Singapore longitudinal ageing studies (SLAS). J Am Med Dir Assoc 2017;18:252-8.

26 Nang EEK, Gitau Ngunjiri SA, Wu Y, et al. Validity of the International physical activity questionnaire and the Singapore prospective study program physical activity questionnaire in a multiethnic urban Asian population. BMC Med Res Methodol 2011;11:141.

27 Mei Na T, Nair R, Di Ying JN, et al. Oral health status and complete denture status of independent-living Singaporean elderly residing in a community home. Singapore Dent J 2014;35:9-15.

28 Thean HPY, Wong ML, Koh GCH, et al. Oral health status and treatment needs of elderly residents in a Singapore nursing home. Ann Acad Med Singapore 2009;38:282-3.

29 Nyunt MSZ, Fones C, Niti M, et al. Criterion-based validity and reliability of the geriatric depression screening scale (GDS-15) in a large validation sample of community-living Asian older adults. Aging Ment Health 2009;13:376-82.

30 Yan Y, Xin T, Wang D, et al. Application of the geriatric anxiety Inventory-Chinese version (GAl-CV) to older people in Beijing communities. Int Psychogeriatr 2014;26:517-23.

$31 \mathrm{Yu}$ J, Collinson SL, Liew TM, et al. Super-cognition in aging: cognitive profiles and associated lifestyle factors. Appl Neuropsychol Adult 2019;22:1-7.

32 Balan P, He H-G, Cao F, et al. Oral health in pregnant Chinese women in Singapore: a call to go beyond the traditional clinical care. Health Care 2018:6:77.

33 Liew TM, Yap P, Ng T-P, et al. Symptom clusters of subjective cognitive decline amongst cognitively normal older persons and their utilities in predicting objective cognitive performance: structural equation modelling. Eur J Neurol 2019;26:1153-60.

34 Feng L, Chong MS, Lim WS, et al. The modified Mini-Mental state examination test: normative data for Singapore Chinese older adults and its performance in detecting early cognitive impairment. Singapore Med J 2012;53:458-62.

$35 \mathrm{Ng}$ T-P, Niti M, Chiam P-C, et al. Ethnic and educational differences in cognitive test performance on Mini-Mental state examination in Asians. Am J Geriatr Psychiatry 2007;15:130-9. 
36 Lee CKY, Collinson SL, Feng L, et al. Preliminary normative neuropsychological data for an elderly Chinese population. Clin Neuropsychol 2012;26:321-34.

37 Seng BK, Luo N, Ng WY, et al. Validity and reliability of the Zarit burden interview in assessing caregiving burden. Ann Acad Med Singapore 2010;39:758-63

38 Tsai P-S, Wang S-Y, Wang M-Y, et al. Psychometric evaluation of the Chinese version of the Pittsburgh sleep quality index (CPSQI) in primary insomnia and control subjects. Qual Life Res 2005;14:1943-52.

39 Tan A, Yin JDC, Tan LWL, et al. Predicting obstructive sleep apnea using the Stop-Bang questionnaire in the general population. Sleep Med 2016;27-28:66-71.

40 Park N, Peterson C, Ruch W. Orientations to Happiness and life satisfaction in twenty-seven nations. J Posit Psychol 2009;4:273-9.

41 Gao F, Ng G-Y, Cheung Y-B, et al. The Singaporean English and Chinese versions of the EQ-5D achieved measurement equivalence in cancer patients. J Clin Epidemiol 2009;62:206-13.

42 Lim HA, Mahendran R, Feng L, et al. Intergenerational transmission of parenting styles of the Chinese living in Singapore. Psychreg $J$ Psychol 2016;1:39.

43 Singapore Statutes Online. Human biomedical research act, 2015. Available: https://sso.agc.gov.sg/Act/HBRA2015 [Accessed Oct 2019].

44 Niti M, Yap K-B, Kua E-H, et al. Physical, social and productive leisure activities, cognitive decline and interaction with APOEepsilon 4 genotype in Chinese older adults. Int Psychogeriatr 2008;20:237-51.

45 Chai YL, Yeo HK-H, Wang J, et al. Apolipoprotein $\varepsilon 4$ is associated with dementia and cognitive impairment predominantly due to Alzheimer's disease and not with vascular cognitive impairment: a Singapore-Based cohort. J Alzheimers Dis 2016;51:1111-8.

81 Feng L. Ageing in a Community Environment Study (ACES) Cohort. In: Pachana N, ed. Encyclopedia of Geropsychology. Singapore: Springer, 2017: 233-8.

47 Thang LL, Lim E. Seniors living alone in Singapore. A report by FeiYue community services, 2012Retrieved from. Available: https:// www.fycs.org/our-work/research/Singapore [Accessed Oct 2019].

48 Taylor HR. Applying new design principles to the construction of an illiterate E chart. Am J Optom Physiol Opt 1978;55:348-51.

49 Ishihara S. Tests for Color-blindness. Handaya Tokyo: HongoHarukicho, 1917

50 Mangione CM, Lee PP, Gutierrez PR, et al. Development of the 25-item National eye Institute visual function questionnaire. Arch Ophthalmol 2001;119:1050-8.

51 Mahoney FI, Barthel DW. Functional evaluation: the BARTHEL index. Md State Med J 1965;14:61-5.

52 Lawton MP, Brody EM. Assessment of older people: selfmaintaining and instrumental activities of daily living. Gerontologist 1969;9:179-86.

53 Bechtol CO. Grip test; the use of a dynamometer with adjustable handle spacings. J Bone Joint Surg Am 1954;36-A:820-4.

54 Katz-Leurer M, Fisher I, Neeb M, et al. Reliability and validity of the modified functional reach test at the sub-acute stage post-stroke. Disabil Rehabil 2009;31:243-8.

55 Rikli RE, Jones CJ. Development and validation of a functional fitness test for community-residing older adults. J Aging Phys Act 1999;7:129-61.

56 Mathias S, Nayak US, Isaacs B. Balance in elderly patients: the "getup and go" test. Arch Phys Med Rehabil 1986;67:387-9.

57 Podsiadlo D, Richardson S. The timed "Up \& Go": a test of basic functional mobility for frail elderly persons. J Am Geriatr Soc 1991;39:142-8.

58 Middleton A, Fritz SL, Lusardi M. Walking speed: the functional vital sign. J Aging Phys Act 2015;23:314-22.
59 Booth M. Assessment of physical activity: an international perspective. Res Q Exerc Sport 2000;71 Suppl 2:114-20.

60 Steele JG, Treasure ET, O'Sullivan I, et al. Adult dental health survey 2009: transformations in British oral health 1968-2009. Br Dent $J$ 2012;213:523-7.

61 Rubenstein LZ, Harker JO, Salvà A, et al. Screening for undernutrition in geriatric practice: developing the short-form mininutritional assessment (MNA-SF). J Gerontol A Biol Sci Med Sci 2001;56:M366-72.

62 Yesavage JA, Brink TL, Rose TL, et al. Development and validation of a geriatric depression screening scale: a preliminary report. $J$ Psychiatr Res 1982;17:37-49.

63 Pachana NA, Byrne GJ, Siddle H, et al. Development and validation of the geriatric anxiety inventory. Int Psychogeriatr 2007;19:103-14.

64 Lee R, Wong J, Lit Shoon W, et al. Art therapy for the prevention of cognitive decline. The Arts in Psychotherapy 2019;64:20-5.

65 Slade GD. Derivation and validation of a short-form oral health impact profile. Community Dent Oral Epidemiol 1997;25:284-90.

66 Sullivan M, Edgley K, DeHousx E. A survey of multiple sclerosis, part 1: perceived cognitive problems and compensatory strategy use. Can J Rehabil 1990;4:99-105.

67 Morris JC. The clinical dementia rating (CDR): current version and scoring rules. Neurology 1993;43:2412-4

68 Luciana M, Nelson CA. Assessment of neuropsychological function through use of the Cambridge neuropsychological testing automated battery: performance in 4- to 12-year-old children. Dev Neuropsychol 2002;22:595-624.

69 Petersen RC. Mild cognitive impairment as a diagnostic entity. J Intern Med 2004;256:183-94.

70 American Psychiatric Association. Diagnostic and statistical manual of mental disorders. 5 Edn. Arlington: American Psychiatric Association, 2013.

71 Zarit SH, Zarit JM. Instructions for the burden interview. University Park: Pennsylvania State University, 1987.

72 Caballero FF, Miret M, Power M, et al. Validation of an instrument to evaluate quality of life in the aging population: WHOQOL-AGE. Health Qual Life Outcomes 2013;11:177.

73 Buysse DJ, Reynolds CF, Monk TH, et al. The Pittsburgh sleep quality index: a new instrument for psychiatric practice and research. Psychiatry Res 1989;28:193-213.

74 Chung F, Yegneswaran B, Liao P, et al. Stop questionnaire: a too to screen patients for obstructive sleep apnea. Anesthesiology 2008;108:812-21.

75 Diener E, Emmons RA, Larsen RJ, et al. The satisfaction with life scale. J Pers Assess 1985;49:71-5.

76 EuroQol Group. EuroQol--a new facility for the measurement of health-related quality of life. Health Policy 1990;16:199-208.

77 Laidlaw K, Power MJ, Schmidt S, et al. The attitudes to ageing questionnaire (AAQ): development and psychometric properties. Int $J$ Geriatr Psychiatry 2007;22:367-79.

78 McCullough ME, Emmons RA, Tsang J-A. The grateful disposition: a conceptual and empirical topography. J Pers Soc Psychol 2002;82:112-27

79 Martins D, Nicholas NA, Shaheen M, et al. The development and evaluation of a compassion scale. J Health Care Poor Underserved 2013;24:1235-46.

80 Hawthorne G. Measuring social isolation in older adults: development and initial validation of the friendship scale. Soc Indic Res 2006;77:521-48.

77 Williams A, Ota H, Giles H, et al. Young people's beliefs about intergenerational communication: an initial cross-cultural analysis. Communication Research 1997;24:370-93. 